\title{
EXECUÇÃO FISCAL: UM ENFOQUE SOBRE AS PROPOSTAS DE ALTERAÇÃO LEGISLATIVA
}

JOSÉ EUSTÁQUIO DE MELO JÚNIOR 


\title{
EXECUÇÃO FISCAL: UM ENFOQUE SOBRE AS PROPOSTAS DE ALTERAÇÃO LEGISLATIVA
}

\author{
José Eustáquio de Melo Júnior
}

\begin{abstract}
RESUMO
O presente trabalho tem por objetivo analisar alguns aspectos do modelo atual de execução fiscal das dívidas ativas da Fazenda Pública, as questões controvertidas que a envolvem e as propostas legislativas de modificação da execução fiscal e criação da execução fiscal administrativa, em trâmite no Congresso Nacional, apontando algumas de suas inconstitucionalidades e consequências práticas em caso de aprovação, até chegar-se à conclusão a respeito da efetiva validade dessas alterações propostas como solução para a satisfação do débito do Fisco no Brasil. Foi desenvolvido com base em pesquisa bibliográfica, situando-se o tema na área de Direito Tributário.
\end{abstract}

Palavras-chave:

Execução fiscal. Execução fiscal administrativa. Direito Tributário.

\begin{abstract}
This study aims to examine some aspects of the current model of tax enforcement of outstanding debt of the Treasury, the controversial issues that surround and legislative proposals to amend the tax enforcement and creation of tax enforcement administrative, pending in Congress pointing out some of its unconstitutionality and practical consequences in case of approval, to arrive at the conclusion about the actual validity of these proposed changes as a solution to satisfy the debt of the Treasury in Brazil. Was developed based on literature, standing in the subject area of Tax Law.
\end{abstract}

Keywords:

Tax Enforcement. Implementing tax administration. Tax Law

\section{INTRODUÇÃO}

Há alguns anos tem-se noticiado uma preocupação com a queda

\footnotetext{
'Juiz substituto do Estado do Tocantins, em exercício na $2^{\mathrm{a}}$ vara da Fazenda Pública da Comarca de Araguaina.
} 
de arrecadação de tributos pela qual o Brasil está passando e quais seriam as possíveis soluções para contornar o problema e garantir o crescimento do país.

Também muito se tem discutido na atualidade sobre a eficiência do Poder Judiciário no julgamento das lides que lhes são endereçadas, o que tem gerado a apresentação de diversas sugestões de alterações legislativas ao Congresso Nacional com o objetivo de reduzir - e quem sabe acabar - com a chamada morosidade do Poder Judiciário.

No caso da execução fiscal do crédito da Fazenda Pública a história é semelhante: reclama-se diuturnamente da demora do Judiciário na satisfação judicial do crédito cobrado mediante as milhares de ações de execuções fiscais que ocupam os escaninhos das varas judiciais em todo o país e atolam os sistemas informatizados, no caso da execução fiscal virtual.

Nesse contexto, tramitam na Câmara dos Deputados os Projetos de Lei n. 5080/09 e 5081/09 e no Senado Federal o Projeto de Lei n. 10/05 cujo objetivo é a modificação do modelo da execução fiscal e que, em linhas gerais, transfere às Fazendas Públicas parte do procedimento judicial de cobrança do seu crédito, hoje a cargo do Poder Judiciário.

Todavia, pode-se falar em crise de arrecadação de tributos no Brasil? As alterações legislativas propostas são a solução para a redução das execuções fiscais em trâmite no país? Ou melhor: as propostas de alteração da lei aplicáveis à satisfação judicial do crédito tributário aumentarão a arrecadação do Fisco no Brasil? Até que ponto esses projetos de lei são constitucionais? Quais serão as conseqüências práticas da adoção desse novo modelo que está sendo proposto?

Essas são algumas perguntas que o presente trabalho propõe responder, sem, contudo, esgotar o assunto, conduzindo o leitor a uma reflexão sobre as execuções fiscais no país, suas tendências e perspectivas.

\section{REVISÃOTEÓRICASOBRE OTEMA}

A execução fiscal da dívida ativa da Fazenda Pública no Brasil, 
antes da vigência da Lei n. 6.830/80, a Lei de Execuções Fiscais LEF, foi assim resumida por Szklarowsky (2005):

Nas Ordenações, todos os créditos fiscais cobravam-se pela ação executiva, os romanos já aplicavam o processo sumaríssimo à cobrança de todas as dívidas, mesmo às oriundas dos contratos. A Carta de Lei, de 22 de dezembro de 1761, atribuía ao Conselho da Fazenda a jurisdição exclusiva para processar e decidir as execuções das rendas e de todos os direitos e bens da Coroa, de qualquer natureza. O Alvará de 16.12.1774 ordenava proceder executivamente contra os devedores na conformidade dos Regimentos da Fazenda e da Lei do Reino. O Decreto 9885, de 1888 disciplinou o processo executivo, até o advento do Decreto - lei 960/38, tendo este sido substituído pelo CPC, de 1973.

Passados quase 30 anos desde a vigência da LEF e considerando ainda o crescimento populacional no Brasil nesse período, que trouxe como conseqüência inexorável o aumento dos créditos das Fazendas Públicas, discute-se a necessidade de modificação do rito da execução fiscal e defende-se a transferência de parte dele para as próprias Fazendas Públicas, através da chamada execução fiscal administrativa.

As principais alegações dos defensores da execução fiscal administrativa sedimentam-se na crise de arrecadação pela qual passam as Fazendas Públicas e na morosidade do Poder Judiciário.

\subsection{Crise de arrecadação de tributos no Brasil?}

As Fazendas Públicas no Brasil detêm cerca de R $\$ 800$ bilhões de créditos para serem satisfeitos, segundo declaração do Procurador da Fazenda Nacional, Estéfano Gimenez Nonato, Chefe da Divisão de Grandes Devedores da Procuradoria da Fazenda Nacional da $3^{a}$ Região. ${ }^{2}$

Diante dessa constatação, alguns setores da sociedade têm afirmado existir uma "crise de arrecadação" de tributos no Brasil.

\footnotetext{
${ }^{2}$ Esse dado foi informado por ocasião do Curso de Aperfeiçoamento para Magistrados em Execução Fiscal, ministrado pela Escola Nacional da Magistratura e Escola de Magistrados da Justiça Federal da 3ª Região, em São Paulo, nos dias 17 e 18 de junho de 2010.
} 
Capriolli (2010), todavia, noticiou que o recolhimento das receitas administrativas tem melhor desempenho para meses de maio, neste ano de 2010:

A arrecadação dos Tributos Federais administrados pela Receita somou em maio R $\$ 59,2$ bilhões, crescimento de $21,08 \%$ sobre o mesmo período do ano passado. No ano, as receitas administradas cresceram $17,33 \%$ e totalizaram R\$ 305,1 bilhões. O recolhimento das receitas administrativas teve o melhor desempenho para os meses de maio em toda a série histórica da Receita.

No mês de fevereiro, Lima (2010) já havia noticiado algo semelhante quando informou que a arrecadação de impostos e contribuições federais é recorde para fevereiro:

A arrecadação total de impostos e contribuições federais atingiu em fevereiro R\$ 53,541 bilhões, valor recorde para esse mês, segundo informações divulgadas ontem $(18 / 3)$ pela Receita Federal. O resultado representa uma queda de $27,25 \%$ em relação ao de janeiro e um aumento de $13,23 \%$ na comparação com o de fevereiro do ano passado.

A arrecadação de impostos administrada pela Receita Federal em fevereiro, que não inclui os demais órgãos federais, já zerou as perdas registradas no ano passado, corrigidas pela inflação, em $0,21 \%$, segundo números divulgados pelo Ministério da Fazenda. A estimativa é que este ano o volume total de impostos arrecadados fique acima de $12 \%$ em relação a 2009 , período em que o país sofreu as consequências da crise econômica mundial, informou o secretário da Receita Federal Otacílio Cartaxo.

Por outro lado, porém, não se pode negar que tenha havido uma retração da arrecadação de tributos no Brasil nos últimos anos e décadas, conforme mencionado por Euzébio (2009), citando Piscitelli, e por Lima (2010) que apontou uma queda de 7,26\% na arrecadação em janeiro de 2010 sobre o mesmo período do ano passado, já corrigido pelo Índice de Preço de Consumidor Amplo (IPCA).

Dados do IPEA, Instituto de Pesquisa Econômica Aplicada, divulgados em Nota Técnica da DIMAC-IPEA ${ }^{3}$ chegaram a essa

${ }^{3}$ Esses dados foram publicados no site:

http://www.ipea.gov.br/sites/000/2/publicacoes/notastecnicas/notastecnicas25.pdf. 
mesma conclusão e explicou alguns motivos da queda de arrecadação no ano de 2009 no Brasil:

Tanto a análise descritiva quanto a econométrica corroboram a hipótese de que a queda verificada na arrecadação federal é explicada fundamentalmente pelas variáveis econômicas, uma vez excluídos das comparações os fatores atípicos que influenciaram a queda da arrecadação de 2009 , notadamente as desonerações e compensações tributárias.

Dessa forma, a arrecadação de tributos no Brasil tem passado por várias transformações nos últimos anos, mas classificar esse quadro como crise de arrecadação encerra certo exagero gramatical e não pode justificar, por si só, alterações profundas da legislação processual referente às ações de execuções fiscais a ponto de criar uma execução físcal a cargo das próprias Fazendas Públicas.

\subsection{Modelo atual da execução fiscal}

Conforme já consignado, a execução fiscal no país é regida hoje pela Lei n. 6.830/80, a chamada Lei de Execução Fiscal - LEF, que prevê em seus artigos $8^{\circ}$ ao 26 o rito judicial a ser seguido para a satisfação do crédito das Fazendas Públicas.

Em breve síntese, emitida a certidão da dívida ativa, título executivo extrajudicial, por meio de processo administrativo a cargo das próprias Fazendas Públicas, o devedor é citado para, no prazo de 5 dias, pagar ou garantir a execução, por meio de depósito em dinheiro, fiança bancária ou penhora de bens próprios ou de terceiros. $\mathrm{O}$ art. 11 da LEF estabelece a ordem de preferência de nomeação de bens à penhora. Depois de citado o executado e garantida a execução, ${ }^{4}$ abre-se o prazo de 30 dias para a oposição de embargos do devedor. Recebidos os embargos, o juiz mandará intimar a Fazenda, para impugná-los no prazo de 30 dias, designando, a seguir, audiência de instrução e julgamento, salvo se tratar-se de matéria de direito ou de direito e de fato, neste último caso sendo a prova exclusivamente documental, caso em que será

${ }^{4} \mathrm{O}$ art. $16, \S 1^{\circ}$, da LEF assevera que "não são admissíveis embargos do executado antes de garantida a execução". 
prolatada sentença no prazo de 30 dias. Não sendo opostos embargos ou sendo eles rejeitados, tendo havido garantia de bens de terceiros, ele é intimado, sob pena de contra ele prosseguir a execução nos próprios autos, para, no prazo de 15 dias, remir o bem, se a garantia for real ou pagar o valor da dívida, juros e multa de mora e demais encargos, indicados no título executivo, pelos quais se obrigou se a garantia for fidejussória.

Estabelece a LEF que a penhora deve ser precedida de termo ou auto que conterá a avaliação dos bens penhorados, efetuada por quem o lavrar. Portanto, entende-se que a penhora, na execução fiscal, é ato privativo do Poder Judiciário, seja por meio de oficial de justiça ou pelo escrivão depois da conversão do bloqueio realizado pelo Sistema Bacenjud, nos termos do art. 655-A do CPC, aplicado subsidiariamente à lide executiva fiscal, nos termos do art. $1^{\circ}$ da LEF. E assim o é porque a penhora, enquanto constrição de bens do devedor, é ato privativo do Poder Judiciário, nos termos do art. $5^{\circ}$, inciso XXXV, da CF/88.

Desde há muito tempo, há reclamação no meio jurídico sobre esse modelo consagrado na LEF. Para alguns, o Poder Judiciário não detém capacidade de entregar a desejável prestação jurisdicional às Fazendas Públicas, no caso específico, a satisfação do débito de responsabilidade do contribuinte, em virtude de sua morosidade, oriunda da sua falta de estrutura, de serventuários, de magistrados etc. Para outros, o próprio rito consagrado na LEF encontra-se defasado e necessita de profundas alterações para que haja a satisfação do crédito das Fazendas Públicas.

\subsection{Tentativas de modificação legislativa}

A retração da arrecadação das Fazendas Públicas e a morosidade do Poder Judiciário fizeram com que alguns segmentos do meio jurídico passassem a defender a alteração do modelo da execução fiscal, na tentativa de assegurar maior efetividade à lide executiva.

Szklarowsky (1997) já defendia a possibilidade de penhora administrativa em seu artigo "A execução fiscal e a penhora administrativa", quando asseverou:

O nobre e operoso Senador, Lúcio Alcântara, honrou- 
nos, muitíssimo, ao adotar a tese que vimos esposando, há mais de duas décadas, apresentando projeto de lei que institui a penhora administrativa executada por órgão jurídico da Fazenda Pública, que, entretanto, poderá optar por executar a dívida ativa nos moldes da Lei de Execução Fiscal vigente (Cf. Projeto de Lei do Senado Federal 174, de 1996, in Diário do Senado de 8.8.96).

Paralelamente aos projetos de lei que alteraram substancialmente o Código de Processo Civil, como, por exemplo, o Projeto de Lei n. 4497/2004, que deu origem à Lei n. 11.382/06 e cuidou da reforma do processo executivo no CPC, havia projeto de lei para modificar a LEF, ${ }^{5}$ mas essa proposta fora rejeitada no âmbito do Congresso Nacional.

Esse fato, porém, não desanimou os defensores da reforma da LEF e outros Projetos de Lei foram apresentados, tanto no âmbito da Câmara dos Deputados como no Senado Federal.

\section{ANÁLISE CRÍTICA DAS INOVAÇÕES DOS PROJETOS DE LEI}

\subsection{Projetos de Lei n. 5080/09 e 5081/09 da Câmara dos Deputados}

O reclamo do meio jurídico, principalmente dos próprios Procuradores da Fazenda Pública, em face do atual modelo da execução fiscal, incitou o legislador e foram apresentados alguns projetos de lei na Câmara dos Deputados e no Senado Federal com a intenção de alterá-lo.

Nesse ponto, encontram-se em tramitação na primeira Casa Legislativa os Projetos de Lei n. 5080/09 e 5081/09, que dispõem sobre a remodelagem da execução fiscal. Existe um outro Projeto de Lei n. 5082/09 que cuida da transação tributária, nas hipóteses que especifica, todavia, essa proposta não é objeto do presente trabalho.

Em resumo, de novo, o Projeto de Lei n. 5080/09 prevê a criação de um cadastro interligado dos órgãos de registro público, sob a supervisão do Ministério da Fazenda, denominado Sistema

\footnotetext{
'Projeto de Lei do Senado n. 174 de 1996, de iniciativa do Senador Lúcio Alcântra.
} 
Nacional de Informações Patrimoniais dos Contribuintes (SNIPC), cuja atribuição consistirá no acesso e na coleta de informações dos contribuintes. Cria-se, portanto, um sistema de investigação patrimonial e financeira do contribuinte. Ainda cria a figura dos oficiais de justiça da Fazenda Pública, com fé pública como os oficiais de justiça do Poder Judiciário e com autorização para realizar constrições, inclusive arrombamentos, mediante ordem judicial. A notificação do contribuinte interromperá o lapso do lustro prescricional e o devedor poderá solicitar o parcelamento do débito, prestar garantia integral do débito por meio de depósito administrativo ou fiança bancária. Haverá a possibilidade de constrição administrativa, seguida da avaliação dos bens, a partir de quando terá a Fazenda Pública o prazo de 30 (trinta) dias para ajuizar a execução fiscal. No despacho inicial, o juiz competente deverá manifestar-se sobre a penhora administrativa e a sua conversão em penhora. Ao contribuinte será facultado opor impugnação quanto à constrição administrativa e opor embargos à execução após a citação, nos moldes da execução por quantia certa contra devedor solvente, prevista no CPC. Também tem a possibilidade de questionar judicialmente, por meio de ação autônoma, a ser ajuizada perante o Juízo da execução físcal, a legitimidade da dívida cobrada. Enfim, impõe a apreciação apenas posterior, pelo Poder Judiciário, dos atos praticados administrativamente.

O Projeto de Lei n. 5081/09, por sua vez, estipula, de importante e inovador, a figura das garantias extrajudiciais, descritas no seu Capítulo I, nas seguintes modalidades: depósito em dinheiro, fiança bancária ou seguro-garantia, hipoteca de bens imóveis e fiança oferecida pelos responsáveis tributários previstos nos arts. 134 e 135 do CTN. Essas garantias são convertidas em judiciais depois do ajuizamento da ação executiva fiscal, que deverá ocorrer no prazo de 30 dias depois de efetivada a garantia. Ainda existe a previsão de oferta de bens imóveis para pagamento da dívida, com a possibilidade de arrematação ou dação em pagamento de leilão extrajudicial. Cabe à Caixa Econômica Federal o recebimento da oferta de bens para leilão extrajudicial que deverá ser instruída com os documentos descritos na proposta. Cabe a esse banco a avaliação do imóvel, no prazo de 10 dias úteis a contar da oferta, o respectivo aceite para alienação e a notificação do devedor para se manifestar 
sobre a avaliação no prazo de 5 dias úteis. Não havendo aceitação da avaliação, o procedimento de oferta de bens é encerrado. Caso contrário, a Caixa Econômica Federal deverá providenciar a formalização da hipoteca em favor da União, encaminhando os documentos necessários para a alienação do bem e indicando a data da hasta pública para a unidade da Procuradoria-Geral da Fazenda Nacional. Os custos do procedimento serão do proprietário do bem e do devedor ou co-responsável. Deverá ser publicado edital no prazo de 15 dias úteis e o primeiro leilão deverá ser realizado em prazo não inferior a 30 dias, contados da primeira publicação. Realizado o leilão, a arrematação poderá ser satisfeita em parcelas e extingue o crédito inscrito em dívida ativa pelo valor constante do auto de arrematação, deduzida a remuneração do banco, restaurando-se a cobrança do saldo remanescente. A proposta ainda previu a possibilidade de conversão do leilão extrajudicial em dação em pagamento de bens imóveis e a preferência dos órgãos públicos em caso de mais de um deles interessar-se pela aquisição do imóvel. Semelhante ao leilão extrajudicial, a dação em pagamento extingue o crédito em dívida ativa pelo valor constante do respectivo auto, deduzida a remuneração da Caixa Econômica Federal, restaurandose a cobrança do saldo remanescente. Também existe a previsão de parcelamento da dívida de pequeno valor, a cargo da ProcuradoriaGeral da Fazenda Nacional, considerada aquela fixada em ato do Ministro da Fazenda e que, na data do pedido de parcelamento, decorra de consolidação de todos os débitos inscritos em dívida ativa da União, com exigibilidade suspensa ou não, inclusive os débitos oriundos de parcelamentos anteriormente rescindidos. Esse pedido de parcelamento fica condicionado ao pagamento da primeira parcela até o último dia útil do seu requerimento.

\subsection{Projeto de Lei n. 10/05 do Senado Federal}

Finalmente, o Projeto de Lei n. 10/2005, de iniciativa do Senador Pedro Simon, que tramita no Senado Federal, "Institui a penhora administrativa, por órgão jurídico da Fazenda Pública, e dá outras providências". Previu a faculdade de a Fazenda Pública executar a dívida ativa nos moldes da LEF ou segundo o rito previsto no projeto. Notificado o devedor para pagamento, no prazo de 5 
dias, a sua inércia poderá ensejar a penhora administrativa a ser levada a efeito por servidor da própria Procuradoria da Fazenda Pública. Em caso de pagamento do crédito, a penhora será desfeita, imediatamente, devendo essa tomar providências cabíveis, no prazo impostergável de quarenta e oito horas, sob pena de responsabilidade de quem der causa à omissão. Realizada a penhora, o devedor poderá oferecer embargos, na forma da Lei $\mathrm{n}^{\circ} 6.830$, de 1980, perante o juiz competente para a execução judicial da Dívida Ativa da Fazenda Pública, o qual requisitará, de ofício, o processo administrativo em que se tiver efetivado a ordem de inscrição e a respectiva penhora administrativa. A Procuradoria ou o órgão jurídico competente deverá encaminhar ao juiz o referido processo, no prazo de quarenta e oito horas, sob as sanções da lei.

\subsection{Críticas aos Projetos de Lei}

De início, entende-se que referidos Projetos de Lei encerram inconstitucionalidade material, pois afrontam o princípio de inafastabilidade da jurisdição, disposto no art. $5^{\circ}, \mathrm{XXXV}$, da Constituição Federal, segundo o qual "A lei não excluirá da apreciação do Poder Judiciário lesão ou ameaça a direito", não havendo como se admitir a transferência à Administração Pública da atividade eminentemente jurisdicional como é o caso proposto, sob pena ainda de violação do princípio da segurança jurídica e do Estado Democrático de Direito. Entende-se, nesse passo, que a proposição apresentada pelo Legislador fere de morte o Princípio da Separação dos Poderes, ${ }^{6}$ pois assegura à Administração Pública a prática de atos eminentemente jurisdicionais.

Ademais, em que pese Szklarowsky (1997) referir-se à penhora como ato administrativo e não jurisdicional, o fato é que a constrição do patrimônio do devedor deve ser ato privativo do Poder Judiciário, órgão imparcial e que detém melhores condições para realizá-la.

Além disso, a criação do Sistema Nacional de Informações

\footnotetext{
${ }^{6} \mathrm{Art} .2^{\circ} \mathrm{da}$ Constituição Federal.

'O art. 13 da LEF não deixa dúvidas quanto à realização da constrição pelo Poder Judiciário.
} 
Patrimoniais dos Contribuintes (SNIPC) e de todo o sistema de investigação econômico e financeiro do contribuinte necessitam ser vistos com cautela, uma vez que o ordenamento jurídico prevê o sigilo fiscal do contribuinte, notadamente na Lei Complementar $\mathrm{n}$. 105/01.

Dentre as principais conseqüências da execução fiscal nos moldes citados nos Projetos de Lei, podem-se destacar: a) o aumento do número de demandas no Poder Judiciário, tendo em vista a possibilidade de oposição de diversos incidentes no curso da execução administrativa perante as Fazendas Públicas; b) a violação da razoável duração do processo, introduzida pelo inciso LXXVIII ao art. $5^{\circ}$ da $\mathrm{CF} / 88$; c) a sobrecarga das Fazendas Públicas, que já apresentam um quadro de funcionários deficitário e provavelmente ficarão mais comprometidas com a possível mudança legislativa.

A tramitação desses Projetos de Lei encontra-se sob permanente enfoque das principais instituições ligadas à execução fiscal. A Ordem dos Advogados do Brasil, por exemplo, já se manifestou contrária à sua aprovação, segundo informa Cristo (2010). Em $26 / 01 / 10$, inclusive, a OAB/SP encaminhou uma manifestação ao então Presidente da Câmara dos Deputados, Michel Temer, externando o seu repúdio aos referidos Projetos de Lei, qualificando-os como inconstitucionais e ofensivos ao Estado Democrático de Direito, destacando, ainda, que jamais fora consultada sobre tais proposições.

Vê-se, com clareza solar, que referidos projetos estão em rota de colisão com os arts. $1^{\circ}, 2^{\circ}, 5^{\circ}$, incisos XXXV e LIV, todos da Constituição Federal e se levar-se em conta que já houve uma tentativa frustrada de reforma da LEF nos moldes agora propostos, por ocasião da tramitação do Projeto de Lei do Senado n. 174 de 1996, de iniciativa do Senador Lúcio Alcântra, paralelamente ao Projeto de Lei n. 4497/2004, que deu origem à Lei n. 11.382/06 e cuidou da reforma do processo executivo no CPC, tendo em vista também a exclusão da $\mathrm{OAB}$ da tramitação dessas novas propostas, questiona-se a sua própria legitimidade democrática.

\section{CONCLUSÃO}

Não existe uma crise de arrecadação de tributos no Brasil e 
juntamente com a alegada morosidade do Poder Judiciário não são fatores a justificar, por si sós, a transferência da execução fiscal do Poder Judiciário para as Fazendas Públicas. Referida proposta, consubstanciada nos Projetos de Lei n. 5080/09 e 5081/09, da Câmara dos Deputados e no Projeto de Lei n. 10/05, do Senado Federal, encerram inconstitucionalidades gritantes e atacam somente o efeito de um problema que é o inadimplemento do contribuinte, quando, na verdade, é preciso enfrentar as causas dessa dificuldade de satisfação dos créditos das Fazendas Públicas.

Além disso, as propostas em trâmite no Congresso Nacional, quando muito, limitam-se a transferir o problema do Poder Judiciário para a Administração Pública o que não é a solução.

Diante do quadro acima descrito, de retração da arrecadação da Receita Federal nos últimos anos e das críticas que se fazem ao modelo atual de satisfação judicial dos créditos tributários, pode-se sugerir como soluções: a) a reformulação da LEF; b) a modificação do sistema Bacenjud, de modo a permitir o bloqueio constante de bens do devedor e não apenas o bloqueio no dia do requerimento; c) a citação por edital do executado, de ofício, depois de haver sido realizada a pesquisa de seu endereço pelo sistema Bacenjud; d) a análise de ofício dos efeitos atribuídos aos embargos do devedor (art. 739-A do CPC); e) a aplicação do art. 285-A do CPC aos embargos do devedor, quando cabível; $\mathrm{f}$ ) a melhoria da estrutura do Poder Judiciário, com novas varas privativas de execução fiscal, contratação de mais serventuários e mais magistrados; g) ampliação do quadro de procuradores das Fazendas Públicas e de defensores públicos; h) a reforma tributária; i) a ampliação dos REFIS; j) a redução da corrupção no Brasil, com políticas adequadas de combate.

\section{REFERÊNCIAS BIBLIOGRÁFICAS}

BRASIL. Congresso Nacional. Câmara dos Deputados. Projetos de Lei n ${ }^{\circ}$ 5.080, 5081 e 5082 de 2009. Brasília: Câmara dos Deputados, 2010. Disponível em:

$<$ http://www.camara.gov.br/sileg/Prop_Detalhe.asp?id=440269>. Acesso em: 24 maio 2010. 
BRASIL. Constituição (1988). Texto consolidado até a Emenda Constitucional $n^{\circ} 64$ de 4 de fevereiro de 2010. Brasília: Presidência da República Federativa do Brasil, 2010. Disponível em: $<$ http://www.planalto.gov.br/ccivil_03/Constituicao/_Constitui\%C 3\%A7aoCompilado.htm>. Acesso em: 24 maio 2010.

BRASIL. Lei $n^{\circ} 6.830$, de 22 de setembro de 1980 . Dispõe sobre a cobrança judicial da Dívida Ativa da Fazenda Pública, e dá outras providências. Brasília: Presidência da República Federativa doBrasil, 2010. Disponível em

$<$ http://www.planalto.gov.br/ccivil/leis/L6830.htm>. Acesso em: 24 de maio de 2010.

CAPRIOLLI, Gabriel. Recolhimento das receitas administrativas tem melhor desempenho para meses de maio. Correio Braziliense, Brasília, 22/06/2010. Disponível em:

$<$ http://www.correiobraziliense.como.br/app/noticia182/2010/06/2 2/economia, $\mathrm{i}=19889>$. Acesso em 23/06/2010.

CRISTO, Alessandro. OAB é contra é contra execução fiscal administrativa. JusBrasil Notícias, Brasília, 11/02/2010. Disponível em: < http://www.jusbrasil.com.br/noticias/2084352/oab-e-contraexecucao-fiscal-administrativa $>$. Acesso em 11/07/2010.

EUZÉBIO, Gilson Luiz. Quedas preocupantes. Disponível em $<$ http://desafios2.ipea.gov.br/sites/000/17/edicoes/52/pdfs/rd52not 04.pdf>. Acesso em 11/07/2010.

LIMA, Daniel. Arrecadação de impostos e contribuições federais é recorde para fevereiro.

Disponível em:

$<$ http://www.agrosoft.org.br/agropag/213685.htm>. Acesso em 11/07/2010.

LIMA, Daniel. Arrecadação da Receita Federal cai $7.26 \%$ em janeiro.

Disponível em

$<$ http://agenciabrasil.ebc.com.br/arquivo/node/332614>. 
Acesso em 11/07/2010.

SZKLAROWSKY, Leon Frejda. Exceção de pré-executividade em face da Lei $\mathrm{n}^{\circ} 6.830 / 80$. Proposta de alteração legislativa. Jus Navigandi, Teresina, ano 9, n. 708, 13 jun. 2005. Disponível em: $<$ http://jus2.uol.com.br/doutrina/texto.asp?id=6833>. Acesso em: 11 jul. 2010.

SZKLAROWSKY, Leon Frejda. À luz da Constituição, é possível instituir validamente a execução do crédito tributário por autoridade diversa da jurisdicional? . Jus Navigandi, Teresina, ano 12, n. 1920, 3 out. 2008. Disponível em:

$<$ http://jus2.uol.com.br/doutrina/texto.asp?id=11794>. Acesso em: 11 jul. 2010.

SZKLAROWSKY, Leon Frejda. A execução fiscal e a penhora administrativa . Jus Navigandi, Teresina, ano 1, n. 9, mar. 1997. Disponível em:

$<$ http://jus2.uol.com.br/doutrina/texto.asp?id=1319>. Acesso em: 11 jul. 2010. 